\title{
Valuation of Forestry in Selected Dryland Areas of West Bengal: A Contingent Valuation Approach
}

\author{
Nilendu Chatterjee
}

Department of Economics, Rabindra Bharati University, West Bengal, India

Corresponding author: nilendu_chatterjee@rediffmail.com

\begin{abstract}
The paper attempts to consider the valuation of forest resources using contingent valuation method in the dryland areas of West Bengal. The issue is important as forestry plays a pivotal role so far as dependency on natural resources by the forest-fringe dwellers (the major stakeholders) in the dryland regions of the state is concerned. Both 'dichotomous-choice type' closed ended and open ended cases are considered to examine the willingness to pay by the forest-fringe dwellers to conserve forests in the dryland areas. It has been estimated that the average willingness to pay by the poverty-stricken forest dwellers for the above-mentioned purpose is ₹ 9.62 per month. Given that the stakeholders are poor, the amount of willingness to pay (though low) shows the willingness of the stakeholders to conserve forests as they cannot survive without it.

JEL Classification: Q20, Q23 and Q51
\end{abstract}

Keywords: Dryland Area, Contingent Valuation, Willingness to Pay, Logit Model

The world's drylands are fragile ecosystems due to harsh climatic conditions and growing human pressures. Yet, they constitute some of the world's largest land reserves and provide a wide range of goods and services which are fundamental to the livelihoods of millions of people. There is no single agreed definition of the term 'drylands'. Two of the most widely accepted definitions are those of FAO and the United Nations Convention to Combat Desertification (UNCCD, 2000) ${ }^{1}$. According to the World Atlas of Desertification (UNEP, $1992)^{2}$, drylands have a ratio of average annual precipitation $(\mathrm{P})$ to potential evapo-transpiration (PET) of less than 0.65. In fact, according to the report of Food and Agricultural Organization (FAO) in 1993, drylands are categorized into hyper arid, arid, semi arid and dry sub humid zones not only

\footnotetext{
${ }^{1}$ FAO has defined drylands as those areas with a length of growing period (LGP) of 1-179 days (FAO, 2000a); this includes regions classified climatically as arid, semi-arid and dry sub-humid. If the length of LGP per year is between 1-74 days, then the area is termed as 'arid', if this length is between 75 to 119 days, then the area is termed as 'semi-arid', and if LGP is for 120 to 179 days, then the area is referred as 'dry sub-humid'. ${ }^{2} U N C C D$ accepted the P/PET ratio indicator, provided by World Atlas of Desertification, for defining drylands.
}

on the basis of $\mathrm{P} / \mathrm{PET}$ ratio but also on the basis of rainfall (in mm.). ${ }^{3}$ On the basis of FAO statistics, the percentage share of arid and semi arid categories combined together are the highest among the total dryland areas of the world.

In India out of the total geographical area, almost one-sixth area with $12 \%$ of the population belongs to drought prone areas. At present 74 districts, covering 13 states of the country have been identified as drought prone. Most of the droughtprone areas are found in arid, semi-arid, and subhumid regions of the country, which experience less than average annual rainfall. Broadly, the droughtaffected areas in India can be divided into two tracts. The first tract comprising the desert and the semi-arid regions covers an area of 0.6 million sq.

\footnotetext{
${ }^{3}$ Thus, when P/PET ratio is less than 0.05 and rainfall is less than $200 \mathrm{~mm}$, the dryland is referred to as Hyper arid. Again when P/PET ratio lies between 0.05 to 0.20 with rainfall less than $200 \mathrm{~mm}$. in winter and $400 \mathrm{~mm}$. in summer, it is considered as arid zone. The next categorization is Semi arid zone for which P/PET ratio lies between 0.20 and 0.50 with rainfall less than 200-500 mm. in winter and less than 400-600 mm. in summer. Finally, when P/PET ratio lies between 0.50 and 0.65 with rainfall less than 500$700 \mathrm{~mm}$. in winter and less than 600-800 mm. in summer, it is referred to as Dry sub humid zone.
} 
$\mathrm{km} .{ }^{4}$. The second tract comprises the regions east of the Western Ghats up to a distance of about 300 $\mathrm{km}$ from coast. ${ }^{5}$ Besides these two tracts of scarcity, there are many pockets of drought in India. Some of these are: Tirunelveli district, south of Vaigai River in Tamil Nadu, Coimbatore area in Kerala, Saurashtra and Kutch regions in Gujarat, Mirzapur plateau and Palamu regions respectively in Uttar Pradesh and Jharkhand, Purulia district of West Bengal, Kalahandi region of Orissa. ${ }^{6}$

On the basis of the document regarding "State Agriculture Plan for West Bengal"7, Bankura, Birbhum and West Medinipur districts have been identified as the districts containing red laterite soils which are coarse in texture, highly drained with honeycomb type of ferruginous concentration at a depth of $15 \mathrm{~cm}$ to $30 \mathrm{~cm}$. Soils are acidic in nature and poor nutrient status limit crop productivity. The district of Purulia which is mostly a plateau, like the three other districts mentioned above, soils are acidic in nature and crop productivity is poor due to high slopes. The State Plan of West Bengal has referred to the four districts together as "dryland areas of West Bengal" based on their nature of soil. Out of these dryland areas, Purulia is considered as arid zone and three other districts are considered as semi arid. ${ }^{8}$ These areas also constitute a part of 'Chhotanagpur plateau'. ${ }^{9}$ These four districts are faced with more or less similar problems.

Forestry is one of the main resources, in drylands, that generates income to the people or stakeholders of dryland areas. People are heavily dependent on forest for their livelihoods. The Joint Forest Management Committee (JFMC) has been implementing government laws regarding use of forest products. The dependence on forestry is so high that it cannot be simply described in words. One can say that people of dryland areas 'lives in and

${ }^{4}$ It is rectangle shaped area whose one side extends from Ahmedabad to Kanpur and the other from Kanpur to Jullundur. In this region, rainfall is less than $750 \mathrm{~mm}$ and at some places it is even less than $400 \mathrm{~mm}$.

${ }^{5}$ This area is known as the "rain shadow area" of the Western Ghats; rainfall in this region is less than $750 \mathrm{~mm}$ and is highly erratic. This region is thickly populated and periodic droughts cause considerable suffering and distress.

${ }^{6}$ www.nih.ernet.in/rbis/india information/drought.htm

${ }^{7}$ Prepared by NABARD Consultancy Services Pvt Ltd (NABCONS), West Bengal.

${ }^{8}$ FAO's classification for categories of dryland areas are on the basis of P/PET ratio and also on the basis of rainfall (in $\mathrm{mm}$.). The State Plan of West Bengal has considered FAO's classification. Additionally, the plan has classified agro-climatic region on the basis of soil contents.

${ }^{9}$ Major part of 'Chhotanagpur plateau'lies in Jharkhand. with forests'. Therefore the valuation of forest from the point of view of forest-fringe people of drylands (who are the main stakeholders in this region) is really an important issue. It should throw light on the following facts like: (i) how the stakeholders value the forests for their livelihood, (ii) what they think for its conservation and (iii) what is their idea for its further improvement and sustainable use. In this paper, CVM attempts to catch all these questions by estimating how much the stakeholders are WTP for all these.

The most obvious way to measure nonmarket values is through directly questioning individuals on their willingness-to-pay (WTP) for a good or service. Contingent Valuation Method (CVM) is a popular way of determining this WTP. It is a survey or questionnaire-based approach to the valuation of non-market goods and services. The values obtained for the good or service are said to be contingent upon the nature of the constructed (hypothetical or simulated) market and the good or service described in the survey scenario. The contingent valuation (CV) technique has great flexibility, allowing valuation of a wider variety of non-market goods and services than is possible with any of the indirect techniques. It is, in fact, the only method currently available for estimating nonuse values.

In CVM, usually stratified random sampling has been followed for selection of sample households from the general population. The sample households are then informed about hypothetical occurrence of any negative environmental externality (say in the form of an environmental disaster) and a policy action to abet or to restrict such a negative environmental externality has been suggested. They are then asked how much they would be willing to pay - for instance, in extra utility taxes, income taxes, or access fees - either to avoid such a negative environmental externality. The actual format may take the form of a direct question ("how much?") or it may be a bidding procedure (a ranking of alternatives) or a referendum (yes/no) votes. Economists generally prefer the referenda method of eliciting values since it is one most people are familiar with. The resulting data are then analyzed. The purpose of using CVM is very clear. Natural resources perform several economic functions on which price cannot be assigned. Even if there are announced property rights related to 
ownership of the resource, the rights cannot be properly assigned to the owners. Use of CVM helps to resolve these issues.

Many authors have used CVM technique for valuing various types of forests. Boman, Huhtala, Nilsson, Ahlroth, Bostedt, Mattson \& Gong (2003) have applied CV method in resource acoounting. Leng \&Lei (2011) set out to estimate forest recreational values of Zhangjiajie in China applying CV method. Again Daniel, Brown, King, Richards \& Stewart (1981) have applied CV technique for measuring scenic beauty of forest. Mogas, Riera \& Brey(2008) and Mogas, Riera \& Bennett (2002) have made a comparison of CV method and Choice Modelling in calculating the environmental values of forests. Pouta (2003) in her academic dissertation has showed attitude-behaviour framework in $\mathrm{CV}$ of forest conservation.

The main motivation behind this paper is generated from the fact that most of the works on CVM are done on developed nations. Very few are based on developing nations. Again, almost no work has used this technique for the valuation of environmental resources of drylands. Being a poverty-stricken area, coupled with illiteracy, unemployment, deprivation and political unrest, removal of poverty along with provision of basic amenities in this region is a matter of national economic policy presently in India. Here arises the need for proper valuation as well as maintenance of this very scarce resource for the sake of development of this region. Given the fact that CVM is useful in capturing "nonuse values" of environmental goods, and it has not been used before for the valuation of natural resource of drylands, we have used it for the use and conservation of forestry in the dryland areas of West Bengal. It is a well known fact that the people residing in drylands depend heavily on natural resources, in the presence of very few alternative income opportunities. In this regard, forest has been one of the main sources of earning. So, proper valuation of forest, especially in drylands, demands significance. This has been neglected in the literature. Another motivation of this paper comes from the fact that we have observed that the growth of forest products as well as income from forest products have been decreasing in these areas of drylands over the years. ${ }^{10}$ In a different

\footnotetext{
${ }^{10}$ See Chatterjee and Dinda (2016) for details.
}

paper Chatterjee and Dinda (2016) have found the presence of Beta convergence, both conditional and absolute, in both tests of forest products as well as income from it. So, this might lead to potential threats to the people of these areas, given the fact known that they are highly dependent on forestry, as just mentioned. Under such circumstances it becomes even more important to see how the forestdependent communities are valuating forestry, for their own sake in the long run. Such an attempt has not been made earlier for forestry in the dryland areas of West Bengal. ${ }^{11}$ In order to fill this lacuna, through this paper, we have tried to capture how much people are willing to pay for conservation and further improvement of the forests of drylands of West Bengal by using CV methods.

The remaining part of the present paper is organized in the following manner. Section 2 deals with the objectives and hypotheses of the study. In the next section, that is, Section 3 considers the data base, survey design and methodology of the study. The econometric specification and the results of the study are shown in section 4 . Finally the concluding remarks are made in section 5 .

\section{Objectives and the Hypotheses of the Study}

The major objectives of the present paper can be summarized as follows:

1. To consider the valuation of forestry along with its facility in terms of estimation of willingness to pay for it by the people in the dryland areas of West Bengal.

2. To examine the determinants of willingness to pay (WTP) for conserving forest along with conservation of forest in the dryland areas of West Bengal.

3. To suggest appropriate policies for conservation of forestry in the dryland areas of the state throughout the year.

To achieve these objectives the following hypotheses have been considered in the present study:

1. The bids of the respondents regarding WTP in case of 'single-bounded dichotomous choice closed-ended referendum' a standard experimental bidding game (as followed in

\footnotetext{
II In fact such a type of work is not only missing for forestry in the dryland areas of West Bengal but is also missing for other natural resources in the dryland areas of West Bengal.
} 
case of dichotomous choice random utility models) has been considered in terms of dice throwing.

2. Conservation and use of forestry in our study region implies overall conservation of forestry in the dryland area not only as a 'use value' but also as a 'non-use value'.

3. Estimation of WTP can be considered both in terms of a logit model (with single-bound closed ended referendum for choosing the bids) and OLS method (with open ended referendum). So two WTPs for two different methods are to be estimated.

4. For closed ended referendum estimation of WTP depends mostly on socio-economic variables and also on various dummy variables

5. Comparison of the mean WTPs, obtained from the two different formats, throw light on the presence of anchoring bias in the context of response by the respondents.

\section{Data Base, Survey Design and Methodology}

In our study we want to focus on the problem of willingness to pay for protection and conservation of forestry and further improvement of it and try to connect it with the developmental perspectives of the study area. Our work is based on field survey and is confined to the districts of Pururlia, Bankura and West Medinipur. Here we have followed stratified random sampling technique. The stratification has been done to get those villages of each of the three districts which are severely dependent on forest resources. This has been done on the basis of a pilot survey and after consulting with the local people and panchayat members.

For selecting the villages after the pilot survey we had in mind about the categorization of drylands of West Bengal so that the selected areas (villages) can be categorized as 'plain (non-hilly) dryland' areas and 'hilly dryland' areas. This categorization along with dependency on forestry has been discussed with the local people and the panchayat members and the selection of villages has been made. Once the stratification has been done we have conducted our survey through random sampling. We have selected random sample from each of the selected villages per district. The total households that are selected randomly in the sample are $1 / 3^{\text {rd }}$ of the total household population per village as usually done in case of selection of random sam In Bankura, we have done the survey in two villages -Susunia and Sewlibona. In Purulia, we have conducted our survey in Murguma and Baghmundi and in Chharra. In West Medinipur, our survey has covered two villages, namely, Salboni and Bishnupur.ple. We have conducted our survey in the above-mentioned three different districts, covering 200 households from each of the three districts, so that the total sample size is 600 . Out of 600 households, 300 have been taken from hilly dryland areas and 300 have been taken from non-hilly dryland areas. Susunia and Sewlibona of Bankura and Baghmundi and Murguma of Purulia fall under 'hilly dryland' areas and the remaining villages are in 'non-hilly dryland' areas. So, we have tried to capture the nature of forest dependency and perception of the people of both hilly dryland as well as non-hilly dryland areas, within the drylands of West Bengal. This categorization is shown in the following table.

Table 1: Division of Households for Sample Survey

\begin{tabular}{ccc}
\hline District & Village & $\begin{array}{c}\text { No. of Households used } \\
\text { for sample survey }\end{array}$ \\
\hline Bankura & Susunia & 170 \\
& Sewlibona & 30 \\
Purulia & Murguma & 75 \\
& Baghmundi & 25 \\
& Joypur & 100 \\
West & Salboni & 100 \\
Medinipur & Bishnupur & 100 \\
\hline
\end{tabular}

Source: Primary Data (Year: 2018).

The survey has been conducted between January and March, 2018. We have collected household data on various socio-economic aspects covering their income status, age, sex, years of education, peoples' perception on present condition of forest compared to past, role of Forest Department (FD) and Joint-forest Management Committees (JFMC) in improving and conserving forest, etc. Among the various questions in the questionnaire about forest dependency, one important question is that whether the households are dependent on forestry or not. The answer that we have received is that almost all the households that we have surveyed have replied that they are directly or indirectly forest- 
dependent. All these information have helped us to use CVM for knowing the maximum willingness to pay (WTP) of the households for proper use, development along with conservation of forestry.

For the purpose of valuation, we have used both closed-ended (also known as dichotomous choice) and open-ended formats. From the first format, we have obtained the mean WTP of the respondents, within the "random utility modeling" (RUM) framework. Here the econometric analysis has been done by applying the logit model. The close-ended format helps in bringing out the true preference of the respondents. In case of the latter format, we have used OLS regression technique to know about the variables that influence the maximum WTP. The main advantage of an open-ended question format is that a direct measure of WTP is obtained.

Additionally, the questionnaire also contains supplementary questions to guide respondents to the contingent valuation section and to derive additional explanatory variables required for the regression analysis. The selections of variables which potentially influence WTP are based on previous studies, economic theory and knowledge about the situation in the region. While framing questionnaire and conducting survey, we have followed the guidelines of the NOAA panel.

The number of respondents that have been interviewed in the six villages, taken together from three dryland districts, namely, Bankura, Purulia and West Medinipur, is 600 and the response rate is as high as $100 \%$ which is really a very high figure. High percentage of response rate in our study can be considered as unconventional but it is a good outcome in a developing country. We attribute this high response rate to the "face-to-face in-person interviews" that we have conducted following the suggestions of the NOAA (1993) panel. Such a process of interview helps the respondents in several ways in the understanding of the purpose of the survey clearly. Actually this is an application of experimental game which has been explained in various works of dichotomous choice through bidding game in terms of a dice throwing in the literature. For application of bidding game in terms of dice throwing one can refer to the works of Arrow, K.; Solow, Portney, Leamer, Radner, R. \& Schuman (1993), Hanemann (1984), Haraou, Markandya, Bellu.\& Cistulli (1998), Hoyos \& Mariel
(2010), Banerjee (2001) Saha (2015), Chatterjee (2017) etc. ${ }^{12}$ The method can be explained explicitly on the basis of dice throwing. Since we have followed single bounded dichotomous choice CVM, it is quite natural that a specific representative respondent is offered only one bid, if helshe accepted it then it would be taken as his/ her willingness to pay and in case of not acceptance of the offered bid by the responded, the representative respondent is considered as 'protest bidder'. ${ }^{13}$ For the above kind of analysis it is important to determine the bid first and then to determine how these bids are to be shown to the respondents. We can consider six bids, namely, ₹ 2, ₹ 5, ₹ 8, ₹ 10, ₹ 15 and ₹ 25 . These bid amounts are expressed in terms of payment per month to conserve forest. The bidding (though appears arbitrary) has been done after discussing with the local people through pilot surveys of course after going through the economic condition of the households. This procedure gives us an idea of the maximum and minimum amounts that we should put forward to the respondents as bid amounts (as usually done in case of Dichotomous choice models of CVM). Study of the socio-economic profile of the region is essential for these types of exercises, but keeping in mind the limitation of size of the paper for a journal it has not been explained in detail here.

The next step is to determine the strategy behind the survey. During our survey, we have assigned these six bids in terms of three groups. ₹ 2 and $₹ 5$ have been assigned for 'low bid group'. ₹ 8 and ₹ 10 have been assigned for the 'medium bid group' and the last two bids, i.e. ₹ 15 and ₹ 25, have been assigned for the 'high bid group'. This strategy has been followed arbitrarily in order to get valid responses out of 600 respondents. The question now arises that how to categorize the sample in terms of bid groups. For categorizing the selected sample households on the basis of bid group and also to bring randomness in selection of sample household under each bid group, we have 'first' thrown a dice. It can be done through any other method, say lottery method, to bring randomness in selection. However, throwing of dice or throwing of coin usually are the conventional

\footnotetext{
${ }^{12}$ Chatterjee (2017) followed a similar bidding procedure for valuation of Drinking Water in Dryland Areas of West Bengal by applying CVM. One can refer to Saha (2015) for a similar type of bidding procedure. Saha (2015) followed the methodology as shown by Harou, Markandya, Bellu and Cistulli (1998). However, the present bidding strategy is different from the bidding strategy followed by Saha (2015).

${ }^{13}$ Protest bidders are those who do not prefer the stated programme and therefore provide zero WTP value.
} 
ways of having randomness in selection. We have followed here the throwing of dice method. If the outcome is 1 or 6 , then the household has fallen under 'low bid group', if the outcome of the dicethrow is 2 or 5 , then the household has fallen under 'medium bid group' and lastly if the outcome is 3 or 4 then the household has fallen in the 'high bid group'. The procedure that has been followed is thus purely a random one and this procedure is followed in many works as mentioned above on dichotomous choice CVM model.

After the selection of the household in any one of the three bid groups just mentioned above, we have offered the household only one particular bid. It is to be noted that we have assigned for each bid group two bids. This has already been mentioned earlier. So the question arises which one of the two bids that has been assigned for a bid group is to be assigned to a particular household belonging to that bid group. To bring randomness in this regard we have thrown dice for the 'second' time. This time, if the outcomes of the dice-throwing are odd numbers, that is 1,3 and 5 then the household has been offered 'lower of the two bids' of a certain bid group but if the outcomes of the dice-throw are the even numbers, that is, 2, 4, 6, then the respondent has been offered the 'higher of the two bids' of a certain bid group. Thus for the 'low bid group' if the outcomes are any one of the three possible odd numbers: $1,3,5$, then the respondent has been categorized to accept the bid of ₹ 2 (lower of the two bids), if the outcomes are 'even numbers', that is, 2, 4 or 6 , then the respondent has been offered the bid of ₹ 5 (higher of the two bids). In this case the respondent has been asked whether he or she willing to accept the bid of ₹ 2 and is willing to pay an equivalent amount (i.e. whether the respondent is willing to pay an amount of ₹ 2 per month for conserving forests). If the answer was 'YES', then we consider the WTP for conserving forests as ₹ 2 per month. If the answer is $\mathrm{NO}$ we consider the respondent as a protest bidder. This is also true for the bidding amount ₹ 5 .

We follow the same procedure for other 'bid groups'. For example, when the dice has been thrown in the front of the respondent for the first time if the outcomes are 2 or 5 then the particular respondent is categorized as a part of medium bid group. In the next step again, just described above, the dice has been again thrown for the second time and if the outcomes are any of the three possible 'odd numbers', then the respondent has been offered to accept $₹ 8$, otherwise ₹ 10 , in case the outcomes are any of the three possible 'even numbers' of the dice. Here also we find that if the answer is YES for any of the two bids as mentioned above then we can determine the bidding amount. If the answer is NO for each of the above-mentioned two bids then we again consider the respondents as protest bidders. The same procedure is true for the 'high-bid' group. These procedures have been followed for bringing randomness both in terms selection of a particular household in a certain bid group and offering a certain bid to that household. There is some 'anchoring bias' in the system but this 'anchoring bias' has been taken care of at the end of section 4 of this paper. In this way a particular bid has been shown to a particular respondent from different events when the events are mutually exclusive, equally likely and independent. So, for a particular respondent, we have thrown a dice twice, firstly, for randomly selecting the bid-group for each and every respondent and, secondly, for randomly selecting the amount of bid that has been offered to the respondent. ${ }^{14}$ This is the standard procedure that is followed in case of closed-ended referendum under single-bound dichotomous choice CVM.

For the open-ended segment of our study we have directly asked the respondents about their maximum willingness to pay (Max WTP). From our survey we have found that 248 respondents are in the group of protest bidders and the rest, that is, 352 are willing to pay for the prescribed programme. From the point of view of methodological part of the paper we followed a random utility model (RUM).This methodological aspect is widely used in the context of the literature on CVM and hence we are mentioning it in brief in the context of the present paper. ${ }^{15}$

This model closely replicates the choices individuals face in a market situation. The respondent is presented with a specific monetary value (e.g. ₹ X) for a policy change and he/she is asked to make a judgment of accepting or rejecting the offer. The size of $\mathrm{X}$ is randomly varied across the sample of a study.

The DC elicitation method provides us only limited ${ }^{14}$ This procedure of throwing a dice twice before offering a particular bid to the respondent was followed for bringing simplicity in the survey process. ${ }^{15}$ We have followed the methodology as shown by Harou, Markandya, Bellu and Cistulli(1998). Interested readers are advised to go through the literature on RUM. See also Harou, Markandya, Bellu and Cistulli(1998). See also Hanemann (1984). 
amount of information about the WTP value of the respondents, namely, "YES" or "NO" answer to a particular bid and nothing more.

If $\operatorname{Bid}$ Amount $(X)>W T P$, then the response is "NO". If Bid Amount $(X) \leq W T P$, then the response is "YES"

We now consider the Random Utility Version of the model. An individual respondent will respond with "YES" if his/her utility from the forest conservation measure is larger than or equal to her utility compared to status quo position; and NO, otherwise.

$\left(U_{1}-U_{0}\right)>0$, the individual will accept to pay the bid $X$

$\left(U_{1}-U_{0}\right)<0$, the individual will reject to pay the bid $X$

The utility $U$ of the individual is not directly observable (hence the differences are also not directly observable). However, its determinants are observable. Under the two different scenarios, one with the acceptance and other with the rejection of the bid, the following specification of the utility function can be put forward: ${ }^{16}$

$$
\begin{aligned}
& U_{1}(1, y-X ; S)=V(1, y-X ; S)+e_{1} \\
& U_{0}(0, y ; S)=V(0, y ; S)+e_{0}
\end{aligned}
$$

Where, $V($.$) is the utility function without random$ element and $U($.$) is the utility function with random$ element. It is to be noted that in equations (3) and (4) we find $Y=$ total income; $1=$ acceptance of the bid; $0=$ rejection of the bid; $S=$ other socio-economic features; $e=$ random error component due to the limited knowledge of the utility model of the individual by the analyst.

From equations (3) and (4) we can write,

$$
\Delta U=\Delta V-e
$$

where, $\left(U_{1}-U_{1}=\Delta U,\left(e_{0}-e_{1}\right)=e\right.$ and $[\mathrm{V}(1, y-X ; S)$ $-\mathrm{V}(0, y ; S)]=\Delta V$, given equation (5), the inequalities (1) and (2) can be written as,

$$
\Delta V>e \rightarrow \text { Acceptance of } \mathrm{X}
$$

${ }^{16}$ This part briefly describes the theoretical methodology of Harou, Markandya, Bellu and Cistulli (1998) and naturally the methodology part, as mentioned in note 15, is similar to the work of Saha (2015), Chatterjee (2017).
$\Delta V<e \rightarrow$ Rejection of $\mathrm{X}$

There are two types of models for estimating the mean WTP value from the DC bids - the probit and the logit model. Here we have considered a logit model (logistic distribution of the error term) for our purpose. ${ }^{17}$

The probability that the individual agrees to accept the bid is therefore:

$$
P(\text { accept } X)=P(Y=1)=P(e<\Delta V=F(\Delta V)
$$

where $Y$ is the observed dichotomous variable, acceptance $=1$, refusal $=0$.

Assuming that the random variable e follows a logistic probability distribution we can write:

$$
P(\text { accept } X)=F(\Delta V)=1 /[1+\exp (-\Delta V)]
$$

When the individual accepts to pay the proposed bid $X$, its means that the maximum Willingness to Pay (WTP) is greater than the proposed bid X. The probability of acceptance, given a bid $X$, is the probability of individual $W T P>X$. Therefore we can write:

$$
P(\text { accept } X)=P(W T P>X)=1 /[1+\exp (-\Delta V)]
$$

This means that the probability the WTP is less than or equal to $X$ is:

$$
P(W T P<X)=G(X)=1-1 /[1+\exp (-\Delta V)]
$$

Where, $G(X)$ is the probability distribution of the WTP.

The mean of the WTP distribution is commonly assumed to be indicators of the individual WTP.

The mean of the maximum WTP can be calculated using the formula that relates the mean of a random variable to its probability distribution:

$$
E(W T P)=\int_{0}^{\infty}\{1-G(X)\} d X
$$

We also need to specify the theoretical model into a functional form from which the unknown parameters can be estimated. Now we move to econometric analysis of $\mathrm{CV}$ results.

\footnotetext{
${ }^{17}$ The choice of the model depends on the probability distribution of the error term where probit is used if the error term follows a normal distribution and logit is used if the error term follows a logistic distribution. However, most of the studies that used DC format follow the logit model since the difference between the two is minor and the logistic function is simpler to deal with.
} 


\section{Econometric Specification and Results of the Study}

We now want to consider the econometric specification of the DC model for a closed-ended referendum. The purpose is to derive the mean WTP for the forestry of the dryland areas. To estimate the WTP we have used a logit model and we have derived the values for the DC bids used for the respondents.

The logit model ${ }^{18}$ used for the study can be specified by the following equation:

Dependent Variable: $\operatorname{Pr}(W T P) \ln \frac{P_{i}}{1-P_{i}}$

Given, $P_{i}$ as the probability of WTP amount greater

than or equal to an assigned bid. $1 n \frac{P_{i}}{1-P_{i}}$ is the $\log$ odds ratio. ${ }^{19}$

The independent variables used in this model are described in terms of table 2.

Table 2: Description of independent variables of the model

\begin{tabular}{|c|c|}
\hline dc bid & $\begin{array}{l}\text { Bids vector of ₹ } 2 \text {, ₹ } 5 \text {, ₹ } 8 \text {, ₹ } 10 \text {, ₹ } 15 \text { and } \\
₹ 25\end{array}$ \\
\hline income & Total monthly income from all sources \\
\hline family size & Household Size \\
\hline age & Age of the respondent \\
\hline edu yrs & Total years of education of the respondent \\
\hline sex & $\begin{array}{l}\text { Dummy Variable. } 0 \text { for Males and } 1 \text { for } \\
\text { Females. }\end{array}$ \\
\hline caste & $\begin{array}{l}\text { Dummy Variable. } 0 \text { for General Caste, } 1 \\
\text { for OBC, } 2 \text { for SC and } 3 \text { for ST }\end{array}$ \\
\hline dom animals & $\begin{array}{l}\text { Dummy variable. } 0 \text { for having no animal } \\
\text { and } 1 \text { for having any. }\end{array}$ \\
\hline
\end{tabular}

We have used several socio-economic aspects as independent variables by using dummy. It has been done because in a poverty-stricken, backward area it is expected that these aspects can play an important role in the response of the respondents.

The estimated result of the logit model along with marginal effects is shown in terms of table 3.

\footnotetext{
${ }^{18}$ Most of the variables used in this model have been selected after going through the literature on CV technique. We have taken the variable 'Caste' to show people of which caste are more willing to contribute and we have taken the variable 'domestic animal' to see whether the presence of this economic asset influence the willingness to pay or not.

19The ratio of probability of willingness to pay $(P)$ and non-willingness to pay $\left(1-P_{i}\right)$. It is to be noted that as $P_{i}$ increases the log-odds ratio increases.
}

Table 3: Results of Estimated Logit Model

\begin{tabular}{|c|c|c|}
\hline Variable & Coefficient & $\begin{array}{l}\text { Marginal Effects } \\
(d Y / d X)\end{array}$ \\
\hline $\begin{array}{l}\text { dc bid/ close- } \\
\text { ended bid }\end{array}$ & $\begin{array}{c}-0.0775859^{* * *} \\
(-4.19)\end{array}$ & $-0.014928^{* * *}(-2.947)$ \\
\hline income & $\begin{array}{c}0.0017995^{* * *} \\
(8.56)\end{array}$ & $0.000346^{* * *}(5.876)$ \\
\hline family size & $\begin{array}{c}-0.6555937^{* * * *} \\
(-6.56)\end{array}$ & $-0.126136^{* * *}(-4.140)$ \\
\hline age & $\begin{array}{c}-0.0094435 \\
(-0.63)\end{array}$ & $-0.001816(-0.598)$ \\
\hline edu yrs & $\begin{array}{c}0.0907969^{*} \\
(1.71)\end{array}$ & $0.017469^{*}(1.684)$ \\
\hline sex & $\begin{array}{c}-0.3213133 \\
(-1.09)\end{array}$ & $-0.061820(-0.998)$ \\
\hline caste & $\begin{array}{c}-0.2485193^{* *} \\
(-2.05)\end{array}$ & $-0.478151^{* *}(-2.021)$ \\
\hline dom animals & $\begin{array}{c}1.108223^{* * *} \\
(3.43)\end{array}$ & $0.213222^{* * *}(2.734)$ \\
\hline Constant & $\begin{array}{c}-1.9144^{* *} \\
(-1.97) \\
\end{array}$ & \\
\hline Log-likelihood & -198.12291 & \\
\hline LR chi-square & 341.80 & The terms in the \\
\hline Prob $>$ chi-quare & 0.000 & parentheses for both \\
\hline Pseudo $\mathrm{R}^{2}$ & 0.4631 & coefficient and marginal \\
\hline $\begin{array}{l}\text { Total no. of } \\
\text { observations }\end{array}$ & 600 & effects are the $\mathrm{t}$-values \\
\hline
\end{tabular}

Source: Author's Calculations

From table 3 we find that age and sex are insignificant but others are significant. Among the significant variables, dichotomous choice bid has a negative sign before them, indicating the fact that for a unit change in the bid, the probability of willingness to pay or the log-odds ratio falls. The negative coefficient for the bid-vector can be explained on the basis of the fact that as bid values rises in a dichotomous choice framework the probability of YES (or acceptance) decreases. The negative sign of caste signifies the fact that people of general caste are more willing to contribute and as we move from general caste community to OBC, SC and ST respectively, this willingness to contribute decreases. This is also quite expected because, generally, people of so-called lower castes (SC, ST) are very poor. Income has a positive impact on WTP because it is expected that with an increase in income, people of drylands would want to pay more for conserving 
the source of their livelihood. On the other hand, people with lower income are more dependent on forest than others and would require a continuous flow of services from the forest ecology to maintain their livelihood, so they would naturally like to pay for resource usages from the forest. However, their payments might be lower compared to the other groups of respondents. People of high income group are more educated and hence they understand the necessity of preserving the forest because they are also dependent on forestry in various ways. So, their probability of accepting a bid is supposed to be high.

Larger households have smaller per-capita income; again, they have enough numbers of family members to earn from different activities, instead of depending on forest only. So, the variable family size has a negative sign before its coefficient. Education has a positive sign. This is also expected because educated people are more aware about the protection of the forestry. Domestic animal is used as a dummy of economic asset. The coefficient having a positive sign indicates the fact that in the presence of domestic animal, people are in a better economic condition than others. Also the fact that people having livestock get their fodder from the forestry and use forest as the grazing land for free of cost may have contributed to the positive sign of this coefficient. Hence, their WTP is quite high which justifies a high value of the coefficient for domestic animals which is significant with a positive sign. In our model the value of pseudo- $\mathrm{R}^{2}$ is 0.4631 . So, our model gives a good fit. We have performed the test for presence of multicollinearity among the explanatory variables of the estimated logit model. The variance inflation factor $(\mathrm{VIF})^{20}$ and the tolerance ${ }^{21}$ or the model have been estimated and the reported results (Mean VIF 3.64) show that the model does not suffer from severe multicollinearity problem. ${ }^{22}$ The marginal effects model for the above logit equation have also been estimated which shows the rate of change in the probability of willingness to pay due to change in the value

\footnotetext{
${ }^{20}$ Variance inflation factors (VIF) measure how much the variance of the estimated regression coefficients are inflated as compared to when the predictor variables are not linearly related. This is used to describe how much multicollinearity (correlation between predictors) exists in a regression/ logit analysis. When there is no collinearity, VIF will be 1 .

${ }^{21} 1 / V I F$ is known as tolerance.

${ }^{22} \mathrm{As}$ 'the rule of thumb', if $1<V I F<5$, it implies variables are moderately correlated and if $5<V I F<10$, then the variables are highly correlated.
}

of an independent variable $X_{j}(j=1,2 \ldots n)$. This is shown in the last column of table 3 . From table 3 we find that as income changes by one unit, holding other factors constant, the probability of WTP also rises; same explanation applies in case of variables like years of education, family size and domestic animals. The opposite explanation applies to the variables age and sex. For these variables, one unit of change in the independent variables causes the probability for WTP to conserve and develop forestry falls.

We next proceed to find the mean willingness to pay of the close-ended referendum under dichotomous choice model. This is given in the following table (Table 4).

Table 4: Estimation of Mean WTP (DC model under Closed-ended Referendum)

\begin{tabular}{cccc}
\hline Measure & WTP & LB & UB \\
\hline Mean & 11.95 & 8.39 & 17.78 \\
\hline
\end{tabular}

Achieved Significance Level for testing $H_{0}:$ WTP $<=0$ vs. $H_{1}:$ WTP $>0$; LB: Lower bound; UB: Upper bound.

Source: Estimated by author.

The mean WTP of our model is ₹ 11.95 per month, with lower bound of ₹ 8.39 and upper bound of ₹ 17.78 per month. Though the mean WTP, in general, appears to take a low value, but, given the backwardness of our study area and also given the fact that most of the stakeholders considered for our study lie below the poverty line, the mean WTP figure of ₹ 11.95 per month for conservation and further development of the forestry is quite reasonable.

After going through the closed-ended referendum, we have focused on the open-ended referendum. Here, we have directly asked people how much they want to pay to protect and conserve forest, without offering them any bid. So, here the concept of probability to WTP does not apply, rather the concept of maximum WTP does. Here, we have used OLS regression technique to show the factors that determine and influence maximum WTP. The results are shown in terms of table 5 .

Here the same variables that are significant in logit model are also significant here, with same signs before their coefficients. Additionally, Sex as a variable has become significant here, but it is 
insignificant in logit model. So, male respondents are more willing to pay than females. High value of $\mathrm{R}^{2}$ implies the fact that more than $60 \%$ of the variation in dependent variable is explained by the independent variables included in the model. So, in terms of cross-section data one can say that it is a well-fitted model. Also, the t-values suggest that the parameter estimates are significant at $1 \%$ level. ${ }^{23}$ Here also, the problem of multicollinearity is within the tolerable limit of less than 5. (The mean VIF is 4.12). In our OLS model, the mean willingness to pay is ₹ 7.30 per month. The results of the OLS regression model are very much similar to that of the logit model, regarding the signs and nature of parameter estimates. So, there are similarities in the explanation of the dependent variables of both the models.

Table 5: Regression Results of Open-ended Referendum

\begin{tabular}{ccc}
\hline Variables & Coefficients & t values \\
\hline Constant & $-2.248051^{*}$ & -1.69 \\
income & $0.001218^{* * *}$ & 17.61 \\
family size & $-0.3211905^{* * *}$ & -2.75 \\
age & 0.0088898 & 1.97 \\
edu yrs & $0.2750305^{* * *}$ & 4.05 \\
sex & $-1.376143^{* * *}$ & -3.15 \\
Caste & $-0.4848951^{* * *}$ & -2.71 \\
dom animals & $2.136319^{* * *}$ & 5.12 \\
\hline
\end{tabular}

Dependent Variable: max wtp (Open ended maximum WTP).

$N=600 F=130.26$ Prob $>F=0.000$ Adjusted $R^{2}=0.6017$

*** denotes significant at $1 \%$ levels, ${ }^{* *}$ denotes significant at $5 \%$ levels, ${ }^{*}$ denotes significant at $10 \%$ levels.

Source: Author's Calculation.

From the above two analysis, we have got 'two willingness to pay' (one from logit model and the other one from OLS model). We have tested whether these two WTPs converge or not by performing the convergent validity test. Convergent validity refers to the degree to which two measures of constructs, that theoretically should be related, are in fact empirically tested to be related. ${ }^{24}$ From the

\footnotetext{
${ }^{23}$ In our model the F-value of Ramsey Regression Equation Specification Error Test (RESET) is 0.5156 which signifies the fact that the null hypothesis, which is, the model has no omitted variables, is accepted and the alternative hypothesis is rejected. So, our linear model is correctly specified and it has no variable being omitted.

${ }^{24}$ Convergent validity, along with discriminant validity, is a subtype of construct validity. Convergent validity can be established if two similar constructs correspond with one another, while discriminant validity applies
}

perspective of the present study convergent validity for the two formats (viz. open-ended and single bounded dichotomous choice) is an important issue primarily for two reasons - First, to check whether the two formats lead to statistically different values for the WTP and second, to check whether anchoring bias plays a significant role such when the convergent validity is disturbed. We examine the convergent validity test in terms of paired mean tests of the two variables - max wtp \& dc bid. The first variable signifies the open bid elicited by the respondent and the second variable is the bid from dichotomous choice that has been obtained by using the logit regression for each of the respondents. The result of the convergent validity test gives the $t$ value -3.32 , with 599 degrees of freedom. This implies the fact that null-hypothesis is rejected at $5 \%$ level of significance. This result vividly indicates that the mean WTPs obtained from the two different formats are significantly different implying that anchoring bias has occurred in the responds of the respondents.

\section{CONCLUDING REMARKS}

In our close-ended referendum we have found the mean WTP to be ₹ 11.95 per month where as it is 7.30 for the open-ended referendum. In this case, this difference is significant as the test of convergent validity is not passed. Thus our model is free from anchoring bias. We can find an average of the two mean WTPs and name it as 'true WTP, in our model. The 'true WTP' turns out to be ₹ 9.62 per month. One can say that for the sake of their own livelihood in the long run because of the presence of very few alternative income opportunities, people of drylands, despite being poverty-stricken, can bear to pay this minimal amount. This amount though appears to be low, is reasonable given the fact that most of the stakeholders in our study area lives below the poverty line. Conservation and development of forestry would not only provide continuous flow of earning to the forestfringe people but also might open alternative income opportunities through development of

to two dissimilar constructs that are easily differentiated. In our study, the convergent validity is attained when the WTP values from two elicitation formats are not statistically different for a particular valuation situation. Although, in some of the studies it is observed that estimated mean WTPs across different instruments do show a discrepancy. The principal reason for such a difference between the results might be due to the fact that respondents' perception about the two or multiple formats is different. 
infrastructure and tourism. Hence this paper has important policy implications from the point of development of the forestry in the dryland areas of West Bengal, given the fact that our study area holds immense importance in National Politics.

\section{REFERENCES}

Arrow, K., Solow, R., Portney, P.R., Leamer, E.E., Radner, R. and Schuman, H. 1993: 'Report of the NOAA Panel on Contingent Valuation,' Federal Register, 58(10): 4601-4614.

Banerjee, S. 2001. 'Economic Valuation of Environmental Benefits and Costs', in R.N. Bhattacharya edited, Environmental Economics: An Indian Perspective, Oxford University Press (India): 125-161.

Boman, M., Huhtala, A., Nilsson, C., Ahlroth, S., Bostedt, G., Mattson, L. and Gong, P. 2003. 'Applying the Contingent Valuation Method in Resource Accounting: A Bold Proposal', Working Paper, No. 85, June, the National Institute of Economic Research, Stockholm.

Chatterjee, N. 2017. 'Willingness to Pay for Drinking Water in Some Selected Dryland Areas of West Bengal: A Contingent Valuation Approach', Vidyasagar University Journal of Economics, XIX: 14-37.

Chatterjee, N. and Dinda, S. 2016. 'Convergence of Forest Resources in Jangalmahal, West Bengal' in (eds.) Ramesh Chandra Das, Handbook of Research on Global Indicators of Economic and Political Convergence: IGI Global, USA.

Ciriacy-Wantrup, S.V. 1947. 'Capital Return from Soil Conservation Practices', Journal of Farm Economics, 29: 1189-96.
Hanemann, W.M. 1984. 'Welfare Evaluations in Contingent Valuation Experiments with Discrete Responses,' American Journal of Agricultural Economics, 66: 332-334.

Haraou, P., Markandya, A., Bellu, L.and Cistulli, V. 1998. "Environmental Economics and Environmental Policy: A Workbook", published by Economic Development Institute(EDI) of World Bank.

Hoyos, D. and Mariel, P. 2010. 'Contingent Valuation: Past, Present and Future', Prague Economic Papers, 4: 329-343.

Leng, Z. and Lei, Y. 2011. 'Estimate the Forest Recreational Values of Zhangjiajie in China Using a Contigent Valuation Method', Low Carbon Economy, 2: 99-106.

Mogas, J., Riera, P. and Bennett, J. 2002. 'A comparison of Contingent Valuation and Choice Modelling: estimating the environmental values of Catalonian Forests', Occasional Papers, Environmental Management and Development, No.1, Dec.

Mogas, J., Riera, P. and Brey, R. 2008. 'Combining Contingent Valuation and Choice Experiments. A Forestry Application on Spain', Springler Science+Business Media B.V.

Pouta, E. 2003. 'Attitude-Behaviour Framework in Contingent Valuation of Forest Conservation', Publications 12, Department of Forest Economics, University of Helsinki.

Saha, D. 2015. 'Some Economic Aspects of Forestry in the Sunderbans', Unpublished Ph.D Dissertation, Department of Economics, Rabindra Bharati University, Kolkata, India. 
